\title{
PERAN INTERVENSI MINIMAL TIPE ABLASI RADIOFREKUENSI DALAM PENANGANAN NYERI KRONIK
}

\author{
THE ROLE OF RADIOFREQUENCY ABLATION AS MINIMAL \\ INTERVENTION IN MANAGING CHRONIC PAIN
}

Yusak Mangara Tua Siahaan, *Hugo Dwiputra Wiradarma**

\begin{abstract}
Chronic pain is one of the most common complaints in everyday clinical practice. These complaints not only cause disruption to physical functioning, but also to social, mental, and economic functions. Recent studies have demonstrated the potential of interventional therapy, including radiofrequency $(R F)$ ablation in the management of chronic pain. The objective of this procedure is to cause lesions in the neural network that inhibits the transmission of pain signals to the brain. Radiofrequency ablation shows higher levels of pain control and less minimal side effects, thus may be one of the preferred therapy in the management of chronic pain.
\end{abstract}

Keywords: Ablation, chronic pain, radiofrequency

\begin{abstract}
ABSTRAK
Nyeri kronik merupakan salah satu keluhan yang sering ditemui pada praktik klinis sehari-hari. Keluhan ini tidak hanya mengakibatkan gangguan pada fungsi fisik, tetapi juga terhadap fungsi sosial, mental, maupun ekonomi. Penelitian terkini menunjukkan potensi terapi intervensi, termasuk ablasi radiofrekuensi (RF) dalam mengatasi nyeri kronik. Prinsip kerja prosedur ini adalah dengan memimbulkan lesi pada jaringan saraf sehingga menghambat transmisi sinyal nyeri menuju otak. Ablasi RF menunjukkan tingkat kontrol nyeri yang lebih tinggi dengan efek samping yang lebih minimal, sehingga dapat menjadi salah satu terapi pilihan dalam penanganan nyeri kronik.
\end{abstract}

Kata kunci: Ablasi, nyeri kronik, radiofrekuensi

*Departemen Neurologi FK Universitas Pelita Harapan/RS Siloam Lippo Village, Tangerang; **Departemen Neurologi RS Siloam Lippo Village, Tangerang. Korespondensi: dryusaks2002@gmail.com.

\section{PENDAHULUAN}

Nyeri kronik adalah pengalaman sensorik dan emosional yang tidak menyenangkan yang berhubungan dengan kerusakan jaringan yang nyata ataupun tidak nyata selama 3-6 bulan sesudah onset atau setelah melewati masa penyembuhan. Hal ini dirasakan secara kontinu dan terus berlangsung selama bertahun-tahun. ${ }^{1-2}$ Nyeri kronik dialami oleh $10 \%$ populasi dunia, sebanyak 1 dari 10 orang dewasa terdiagnosis kasus baru setiap tahunnya. Salah satu faktor yang paling memengaruhi adalah usia, dengan prevalensi lebih tinggi pada populasi berusia $>70$ tahun. ${ }^{3-4}$

Nyeri kronik terbukti memengaruhi fungsi fisik, sosial, dan ekonomi, termasuk pekerjaan, kegiatan rekreasional, olahraga, dan tidur. Menurut studi Duenas M dkk, Setidaknya sebanyak 24,4\% penderita nyeri kronik di Spanyol meninggalkan pekerjaannya sementara waktu dan $12 \%$ kehilangan pekerjaannya. ${ }^{5-6}$ Biaya yang dihabiskan untuk nyeri kronik di Amerika Serikat mencapai \$560-\$635 miliar per tahunnya, lebih besar dibandingkan penyakit jantung (\$309 miliar), kanker (\$243 miliar) dan diabetes ( $\$ 188$ miliar). ${ }^{?}$

Manajemen nyeri kronik umumnya diawali dengan terapi konservatif seperti misalnya: terapi farmakologis dan fisioterapi. Jika terapi konservatif tidak dapat mencapai derajat pengurangan nyeri yang diharapkan, maka dibutuhkan modalitas lain berupa tindakan intervensi nyeri. ${ }^{8}$ Prosedur ini tidak hanya sebagai terapi kuratif, namun juga dapat dipakai sebagai tindakan diagnostik.

\section{PEMBAHASAN}

Manajemen nyeri kronik merupakan suatu tantangan secara multidisiplin untuk meningkatkan kualitas hidup, yaitu tercapainya pemulihan fungsi gerak, pengurangan penggunaan obat-obatan, serta pencegahan kekambuhan. Hal ini membutuhkan terapi fisik, terapi okupasi, serta intervensi psikologis dan medis. Intervensi medis dapat dibagi menjadi dua, yaitu terapi farmakologis dan terapi nonfarmakologis (invasif). ${ }^{9}$ 
Terapi non-farmakologis (invasif) dapat menggunakan ablasi saraf (denervasi kimiawi, krioneurolisis atau krioablasi, ablasi radiofrekuensi); injeksi blok [injeksi blok sendi, seperti sendi faset (sendi atlanto-aksial dan atlanto-oksipital) dan sendi sakroiliaka]; blok saraf dan akar saraf (seperti blok pleksus seliaka, pleksus hipogastrik, saraf simpatis lumbal, dan simpatektomi paravertebral); stimulasi saraf [neuromodulasi dengan stimulus elektrik (stimulasi saraf subkutan perifer dan medula spinalis) dan stimulasi saraf elektrik transkutaneus/ TENS]; injeksi steroid [epidural dengan/tanpa anestesi lokal, administrasi steroid pada interlaminar dan transforaminal epidural dengan atau tanpa anestesi lokal, terapi obat intratekal (blok neurolitik intratekal, injeksi non-opioid intratekal, dan injeksi opioid intratekal)]; serta invasi spinal minimal (prosedur invasi spinal minimal seperti vertebroplasti, kifoplasti dan dekompresi diskus perkutaneus). ${ }^{10-12}$

Prosedur ablasi radiofrekuensi (RF) atau disebut juga rizotomi merupakan salah satu prosedur invasif minimal dengan menggunakan alat penghasil arus frekuensi tinggi yang menghasilkan panas dengan tujuan untuk membuat lesi pada suatu jaringan, termasuk jaringansaraf. Lesi pada jaringan saraf akan menghambat transmisi sinyal nyeri menuju otak. Penggunaan ablasi ini pertama kali dilakukan oleh Krischner (1931) untuk mengobati nyeri pada trigeminal neuralgia dengan koagulasi termal pada ganglion gasseri. Baru pada tahun 1950 mesin penghasil ablasi RF pertamakali digunakan secara luas. $^{12}$

Radiofrequency merupakan bagian dari gelombang elektromagnetik dengan frekuensi $3 \mathrm{~Hz}$ sampai $300 \mathrm{GHz}$. Alat ini bekerja menggunakan arus frekuensi tinggi yang dihasilkan oleh generator yang berjalan dari elektroda melewati jaringan tubuh menuju ground pad. Terjadinya gelombang elektromagnetik pada ujung elektroda akan menyebabkan pergesekan antar molekul, sehingga friksi yang terbentuk antar molekul ini akan menghasilkan energi panas. ${ }^{13}$ Peningkatan suhu yang dihasikan akan merusak jaringan lokal yang terletak di sekitar ujung elektroda.

Sebagai contoh, kerusakan jaringan saraf akan terjadi pada suhu $>40^{\circ} \mathrm{C}$. Untuk mencapai keseimbangan suhu tersebut diperlukan waktu 30 sampai 60 detik. Kenaikan suhu setinggi $100^{\circ} \mathrm{C}$ akan menyebabkan kematian jaringan secara instan. Kematian jaringan secara cepat ini menyebabkan karbonisasi dan berperan sebagai insulator yang menghambat transfer panas ke jaringan sekitar. Selain dari area karbonisasi, suhu juga dipengaruhi oleh pembuluh darah dan cairan serebrospinal yang berfungsi sebagai regulator yang menyebabkan penurunan suhu pada daerah target terapi. Terhambatnya panas ini akan menyebabkan ketidakcapaian kerusakan target jaringan yang diinginkan. ${ }^{13}$

Prosedur ablasi RF memerlukan akurasi yang tinggi dalam menentukan target jaringan yang akan dirusak dan dapat menghilangkan rasa nyeri dalam jangka waktu yang panjang. Selain dari kerusakan jaringan yang dibentuk, teknik ablasi RF juga dapat menstimulasi sistem saraf, yang berfungsi sebagai proteksi atau petunjuk bahwa target jaringan yang akan diablasi tidak tepat.

Pada tahun 1970-1990, keberhasilan tindakan RF bervariasi $17-82 \%$ pada ablasi saraf cabang medial facet lumbal, karena pengetahuan anatomi pada jaman tersebut sangatlah kurang dan baru berkembang pada 20 tahun terakhir ini. ${ }^{14}$

\section{Teknik Ablasi RF}

Cara yang paling sering dipakai untuk menanggulangi nyeri adalah continuous dan pulsed radiofrequency. Continuous radiofrequency (CRF) adalah tindakan ablasi menggunakan arus listrik frekuensi tinggi secara kontinu dengan suhu $45^{\circ} \mathrm{C}$ atau lebih. Berbeda dengan CRF, kerusakan jaringan yang dihasilkan pada pulsed radio frequency ablation (PRFA) lebih minimal. ${ }^{16-17}$ Pulsed radiofrequency ablation merupakan tindakan ablasi dengan mengirimkan signal (300kHZ) secara intermiten dengan voltase tinggi yang akan mencegah terjadinya peningkatan suhu yang berlebihan dan kerusakan saraf yang luas.
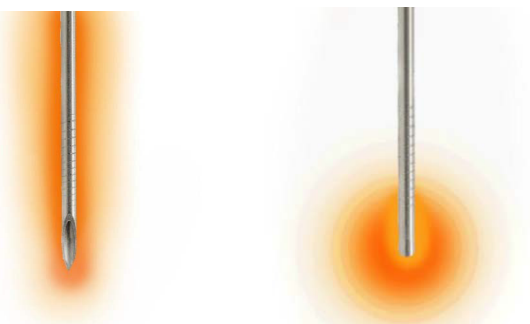

Gambar 1. Arus RF; Heat RF (Kiri) dan Cooled RF (Kanan) 
Tujuan dari prosedur ablasi ini adalah mendenervasi serabut saraf $\mathrm{C}$ tanpa menyebabkan kerusakan pada saraf motorik maupun saraf sensorik. Namun penelitian terbaru menunjukkan bahwa nyeri yang hilang setelah dilakukan PRFA bukan akibat proses neurolitik, namun karena adanya perubahan neuromodulasi pada jaringan saraf yang disebabkan oleh medan listrik, bukan oleh perubahan suhu. ${ }^{13}$ Oleh karena pemanasan pada CRF bersifat kontinu, maka dapat dilihat jaringan saraf yang rusak lebih signifikan bila dibandingkan dengan PRFA yang menyebabkan kerusakan jaringan lebih reversibel. ${ }^{14}$

Radiofrekuensi dapat dibagi menjadi 2 tipe, yakni heat dan cooled RF. Heat RF atau dikenal sebagai RF konvensional memiliki suhu tertinggi pada seluruh pemukaan elektroda yang perlahan menurun ketika menjauhi elektroda dengan target suhu $80^{\circ} \mathrm{C}$. Adapuncooled RF dengan suhu target sebesar $60^{\circ} \mathrm{C}$ memiliki suhu tertinggi pada ujung elektroda dengan jarak 1-2mm (tergantung pada intensitas sinyal RF dan agresivitas pendinginan air) dari elektroda (Gambar 1). ${ }^{15}$

Prinsip ablasi RF pada nyeri kronik adalah terbentuknya lesi pada jaringan target, sehingga input nyeri saraf nosiseptif (A- $\delta$ dan C-fiber) terhambat menuju ke sistem saraf pusat tanpa merusak jaringan saraf motorik maupun sensorik (A- $\beta$ fiber). Besarnya lesi bergantung terhadap ukuran elektroda, suhu yang dihasilkan, durasi dari ablasi, serta konfigurasi jaringan yang diablasi. Lesi yang dibentuk akan berbentuk oval, sejajar dengan ujung jarum elektroda dan tidak melebihi ujung elektroda. Untuk membentuk lesi pada jaringan saraf, ujung jarum harus sejajar atau bersebelahan dengan sel saraf yang akan diablasi.

Proses ablasi dimulai dengan terkoagulasinya jaringan saraf diikuti dengan reaksi inflamasi dan penimbunan kolagen yang memakan waktu 3 minggu. Selama proses tersebut lamina basalis akan tetap intak, sehingga sel saraf dapat tetap beregenerasi. ${ }^{13}$ Tindakan ini telah banyak digunakan sebagai salah satu modalitas tatalaksana nyeri kronik dengan indikasi pada nyeri faset lumbar (zigapofiseal) dan servikal, sendi sakroiliaka, diskus intervertebrata, ganglion radiks dorsalis, serta nyeri wajah (ganglion trigeminal dan sfenopalatina.
Ablasi cabang medial sendi faset lumbar (zigapofiseal) merupakan salah satu tindakan RF ablasi yang sering dilakukan pada kasus nyeri pinggang kronik akibat inflamasi pada sendi faset. ${ }^{14}$ Sebagai contoh Gambar 2 menunjukkan gambaran radiologis target RF sendi faset lumbar cabang medial setinggi L3-L5 dengan proyeksi lateral. Pada 6 penelitian yang menilai efektifitas penggunaan RF pada nyeri sendi faset lumbal ditemukan hasil yang secara statistik signifikan pada 5 penelitian, hanya 1 yang tidak bermakna.

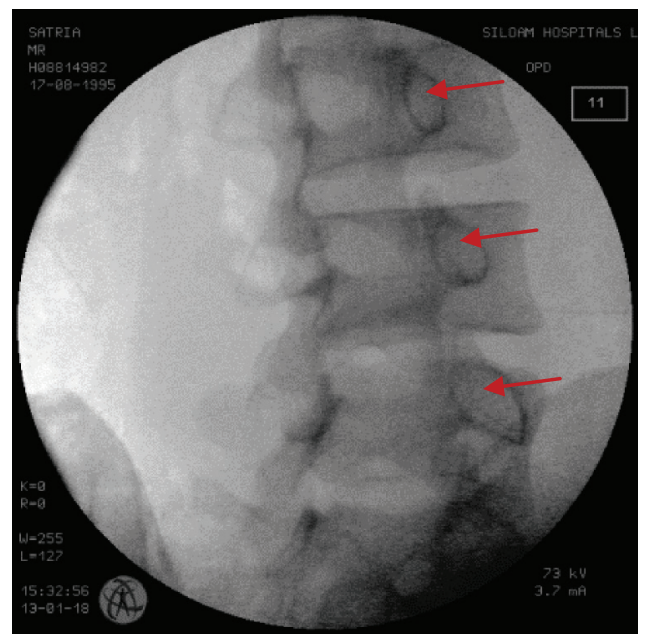

Gambar 2. PRF pada Cabang Medial Sendi Facet Lumbal Setinggi L3-5

Ablasi cabang medial sendi faset servikal dilakukan pada nyeri leher akibat nyeri sendi facet daerah tersebut. Prevalensi nyeri leher kronik servikal ini mencapai $10-24 \%$,separuh diantaranya memiliki riwayat trauma whiplash berhubungan dengan sendi facet servikal (zigapofiseal). Nyeri leher, terbatasnya mobilitas servikal, nyeri bahu, nyeri lengan, dan nyeri kepala dikenal dengan cervical facet syndrome. Ablasi RF merupakan salah satu metode yang dapat digunakan untuk menangani sindrom tersebut dengan mengurangi rasa nyeri dalam jangka waktu yang panjang. Gambar 3 merupakan contoh gambaran radiologis target tindakan $\mathrm{RF}$ sendi faset servikal cabang medial setinggi C3-5 dengan proyeksi lateral. ${ }^{14}$

Ablasi pada diskus intervertebratalis dilakukan pada gangguan diskus intervertebralis yang menjadi penyebab kondisi patologi pada $40 \%$ pasien dengan keluhan nyeri punggung bawah. Prosedur RF yang paling sering dipilih adalah terapi elektrotermal 


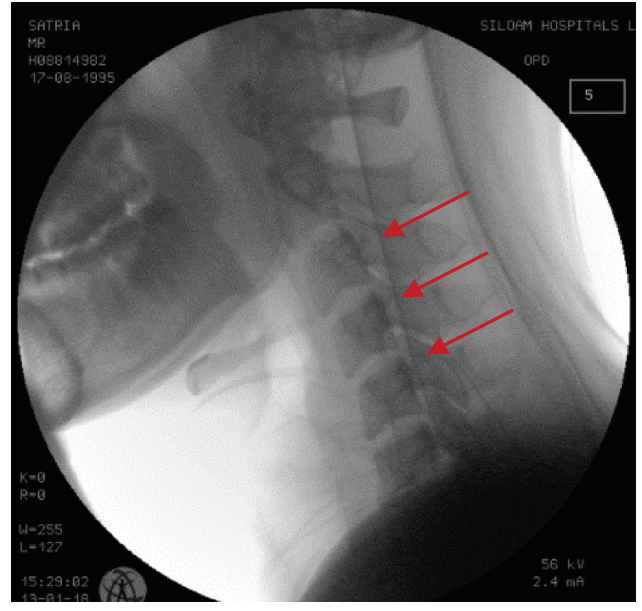

Gambar 3. PRF Cabang Medial Sendi Facet Servikal Setinggi C3-5

intradiskal (IDET), sebuah prosedur yang minimal invasif dengan memberikan gelombang panas $90^{\circ} \mathrm{C}$ pada dinding posterior dan lateral dari diskus. Selain hasil diskografi yang positif, pasien yang menunjukkan hasil yang baik melalui prosedur IDET adalah pasien yang memiliki kriteria tertentu, seperti hasil tes provokatif yang positif, tinggi diskus yang minimal $50 \%$, tidak adanya riwayat disektomi ataupun stenosis kanalis lumbalis, dan tidak adanya gangguan diskus multilevel atau radikulopati kompresif. Biakuplasti intradiskus (intradiscal biacuplasty) menjadi pilihan prosedur lain dalam menangani proses patologi internal diskus. ${ }^{13}$

Ablasi pada ganglion radiks dorsalisatau rhizotomi parsial pada radiks posterior merupakan prosedur yang umumnya dipilih untuk penanganan pasien dengan nyeri radikular sebagai alternatif prosedur operasi. Terapi ini cukup efektif dalam menangani postherpetik neuralgia thorakal, nyeri thorakal pasca-operasi, post-amputation stump pain, dan complex regional pain syndrome (CRPS). ${ }^{19}$ Gambar 4 menunjukkan gambaran radiologis target RF (tanda panah) pada ganglia radiks dorsalis setinggi L5-S1 dengan proyeksi oblik.

Ablasi pada nervus simpatik masih dapat dilakukan, meskipun peran RF ganglion simpatik saat ini telah digantikan oleh stimulasi medula spinalis. Prosedur ini masih digunakan pada kondisi tertentu seperti nyeri iskemik akibat gangguan vaskular perifer oleh karena sifatnya yang dapat memperbaiki aliran darah.

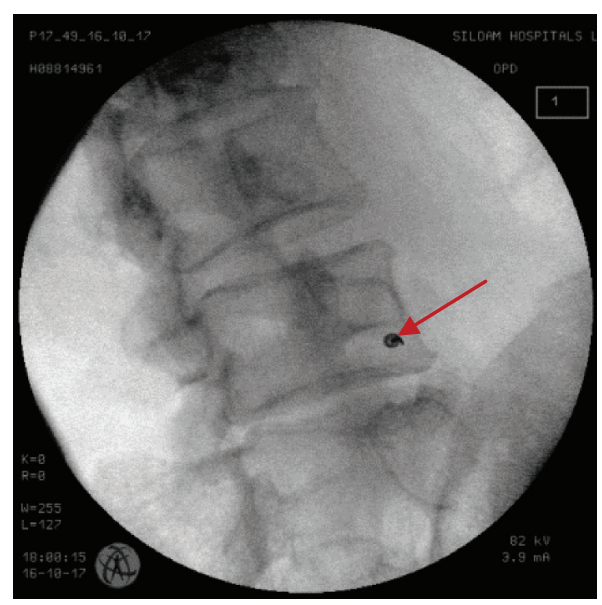

\section{Gambar 4. PRF pada Ganglia Radiks Dorsalis Setinggi L5-S1}

Prosedur RF ganglion simpatik yang umum dilakukan pada tata laksana nyeri kronik adalah ablasi ganglion sfenopalatina (nyeri kepala pascatrauma, nyeri kronik pada wajah, dan nyeri kepala kluster), ganglion servikal superior [tata laksana nyeri wajah atipikal, ablasi ganglion stelata (tata laksana nyeri pada CRPS dan postratumatic stress disorder/PTSD)], ganglion simpatik thorakal (tata laksana nyeri pada CRPS, hiperhidrosis palmar dan compensatory hyperhidrosis of the trunk), ablasi saraf splanknikus (tata laksana nyeri kronik abdomen, pankreatitis kronik, dan nyeri kanker), ganglion simpatik lumbal (tata laksana CRPS, hiperhidrosis plantar, nyeri kronik pelvis dan perineal, serta nyeri kanker). ${ }^{20}$

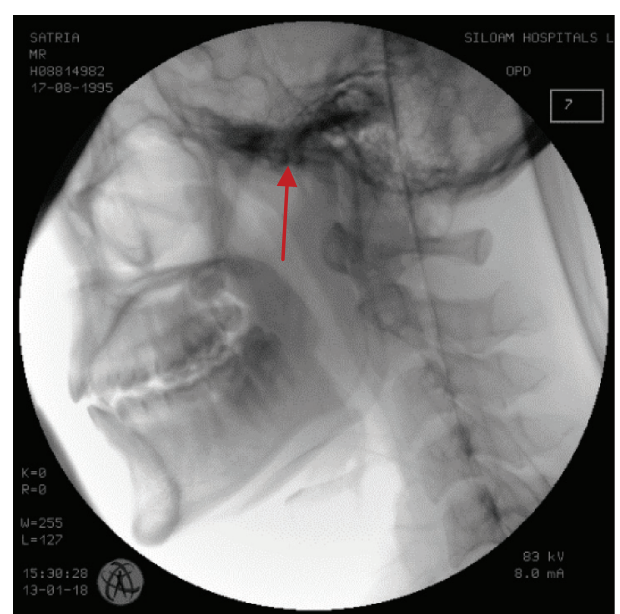

\section{Gambar 5. PRF pada Ganglion Gasserian}

Ablasi ganglion trigeminal dilakukan sebagai salah satu tata laksana nonmedikamentosa neuralgia trigeminal. Target ablasi adalah saraf trigeminal pada 
area foramen ovale. Prosedur ini dapat memberikan perbaikan rasa nyeri sebesar $98 \%$ dari pasien yang menderita neuralgia trigeminal. Namun sebanyak $15 \%-20 \%$ pasien mengalami kekambuhan nyeri dalam rentang waktu 12 bulan setelah tindakan intervensi. Tindakan ablasi dapat diulangi pada pasien yang sama bila nyeri muncul kembali. ${ }^{20}$ Gambar 5 menunjukkan gambaran radiologis target $\mathrm{RF}$ ganglion Gasserian saraf Trigeminal pada kasus neuralgia trigeminal.

Ablasi pada ganglion sfenopalatina merupakan suatu modalitas pengobatan yang dapat digunakan untuk mengobati atau mengurangi gejala nyeri intraktabel pada wajah atau nyeri kepala kluster. Ganglion yang terletak di fossa pterigopalatinaini merupakan struktur ekstrakranial neural terbesar serta mempunyai komponen sensorik, motorik, dan otonom yang merupakan bagian dari patofisiologi terjadinya nyeri kepala kluster (cluster headache).

Tindakan ablasi dilakukan dengan pendekatan infrazigomatika yang dapat dilakukan bila anestesi blok menunjukkan pengurangan nyeri. Namun dari penelitian yang dilakukan oleh Akbas M menunjukkan sebanyak $23 \%$ pasien yang dilakukan ablasi ganglion sphenopalatine tidak mendapatkan perbaikan rasa nyeri yang signifikan. ${ }^{21-22}$ Gambaran radiologis target radiofrekuensi pada ganglion sfenopalatina dengan pendekatan infrazigomatika pada kasus nyeri kepala kluster (Gambar 6).

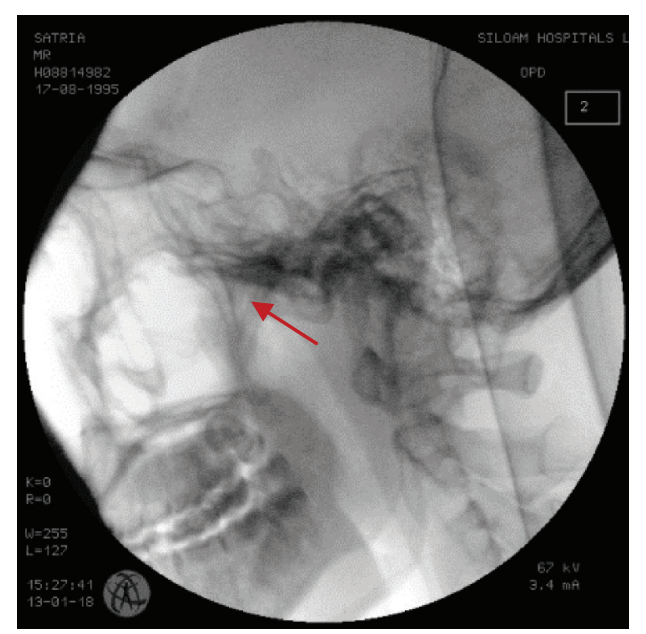

Gambar 6. PRF pada Ganglion Sfenopalatina

Walaupun sangat jarang terjadi, dapat terjadi komplikasi seperti rasa nyeri dan rasa tebal pada area target terapi, luka bakar, alergi, infeksi, neuritis, meningitis, hematothoraks, dan efusi pleura. Meskipun bukan merupakan suatu komplikasi, namun efek samping yang dialami oleh 3-5\% pasien adalah nyeri seperti rasa terbakar yang dapat dirasakan selama 3-5 minggu. ${ }^{13}$

\section{KESIMPULAN}

Ablasi RF merupakanterapi minimal invasif yang dapat menjadi salah satu alternatif tata laksanapada nyeri kronik yang tidak terkontrol melalui terapi medikamentosa, seperti neuralgia trigeminal, nyeri pinggang kronik, hingga nyeri pada kanker. Diperlukan pengetahuan terkait anatomi dan teknik pencitraan yang baik untuk mendapatkan keberhasilan terapi.

\section{DAFTAR PUSTAKA}

1. Treede DR, Rief W, Barke A, Aziz Q, Bennett MI, Benoliel R, dkk. A classification of chronic pain for ICD-11. Pain. 2015;156(6):1003-7.

2. Siahaan YMT. Nyeri. Edisi ke-1. Banten: FK Press Universitas Pelita Harapan. 2018.

3. Fayaz A, Croft P, Langford RM, dkk. Prevalence of chronic pain in the UK: a systematic review and meta-analysis of population studies. BMJ Open. 2016;6(6): 010364.

4. Jackson TP, Stabile VS, McQueen KAK. The global burden of chronic pain. ASA Monitor. 2014;78:24-7.

5. Duenas M, Ojeda B, Salazar A, Mico JA, Failde I. A review of chronic pain impact on patients, their social environment and the health care system. J Pain Res. 2016;9:457-67.

6. Dezutter J, Luyckx K, Wachholtz A. Meaning in life in chronic pain patients over time: associations with pain experience and psychological well-being. J Behav Med. 2015;38(2):384-96.

7. Henschke N, Kamper SJ, Maher CG. The epidemiology and economic consequences of pain. Mayo Clin Proc. 2015;90(1):139-47.

8. Agarwal V. Fitzgerald RT, Rothfus WE. Radiofrequency ablation treatment of chronic neck and low back pain attributable to facet joints. Neurographics. 2014;4:106-13.

9. Amatya B, Young J, Khan F. Non-pharmacological interventions for chronic pain in multiple sclerosis (protocol). Cochrane Database SystRev. 2017;3:CD012622.

10. Gouvinhas C, Veiga D, Mendonca L, Sampaio R, Azevedo LP, Castro-Lopes JM. Interventional pain management in multidisciplinary chronic pain clinics: a prospective multicenter cohort study with one-year follow-up. Pain Res Treat. 2017;2017:1-11. 
11. Tompkins DA, Hobelmann JG, Compton P. Providing chronic pain management in the "Five Vital Sign" era: historical and treatment perspectives on a modern-day medical dilemma. Drug and Alcohol Dependence. 2017;1:S11-21.

12. Lockmann B, Trescot AM, Krashin D. Neurolytic techniques. Dalam: Trescot AM, editor. Peripheral nerve entrapments: clinical diagnosis and management. Edisi ke-1. Switzerland: Springer. 2016. h. 45-58.

13. Soloman M, Mekhail MN, MekhailN. Radiofrequency treatment in chronic pain. Expert Rev Neurother. 2010;10(3):469-74.

14. Hong K, Georgiades C. Radiofrequency ablation: mechanism of action. JVIR. 2010;21(8):S179-86.

15. Alberca AC, Lopez-Riquelme JA, Cortes MDPS. Pain treatment with cooled radiofrequency in osteoarthritis and total knee arthroplasty: case series in hospital Universitario de Son Espases. 2017;2(4):77-83.

16. Kapural L, Mekhail N. Radiofrequency ablation for chronic pain control. Physiol rev. 2012:92(4):1699-775.

17. Kapural L, Nageeb F, Kapural M dkk. Cooled radiofrequency system for the treatment of chronic pain from sacroiliitis: the first case-series. Pain Pract. 2008;8(5):348-54

18. Racz GB, Ruiz-Lopez R. Radiofrequency procedures. Pain Pract. 2006;6(1):46-50.

19. Al-Timimi ASH, M ZM. Gasserian ganglion thermal radiofrequency and alcohol ablation therapy in patients with an idiopathic trigeminal neuralgia of 20 years duration. Mustansiriya Medical J. 2014;13(2):71-4

20. Deniz S, Bakal O, Inangil G. Application of radiofrequency in pain management. Dalam: Prostran M, editor. Pain management. Edisi ke-1. Serbia: Intech; 2016. h. 95-113

21. David Ho KW, Przkora R, Kumar S. Sphenopalatine ganglion: block, radiofrequency ablation and neurostimulation-a systematic review. J Headache Pain. 2017:18(1);118.

22. Akbas M, Gunduz E, Sanli S, Yegin A. Sphenopalatine ganglion pulsed radiofrequency treatment in patients suffering from chronic face and head pain. Brazilian J Anesthesiol. 2016;66(1):50-4. 